\title{
PERSPECTIVES
}

\section{The molecularization of identity: science and subjectivity in the 21 st century}

\author{
IAN VINCENT MCGONIGLE ${ }^{1 *}$ AND RUHA BENJAMIN ${ }^{2}$ \\ ${ }^{1}$ Program on Science, Technology and Society, Harvard University, John F. Kennedy School of Government, 79 JFK Street, Cambridge, MA \\ 02138, USA \\ ${ }_{2}^{2}$ African American Studies, Princeton University, 003 Stanhope Hall, Princeton, NJ 08544, USA
}

(Received 31 May 2016; accepted 1 June 2016)

\begin{abstract}
Summary
Recent advances in biological and computational technologies are changing the way different social groups imagine race, gender, kinship, citizenship and disease risk. Existing taxonomies are being displaced or reconfigured, impacting the ways in which people are governed, how lives are lived, how groups are known and how power is exercised. Herein we report on a two-day international symposium that we co-organized, titled 'The molecularization of identity: science and subjectivity in the 21st century,' that was held on 29-30 April 2016 at the Program on Science, Technology and Society, at Harvard University. The symposium drew upon the tools and expertise from multiple disciplines and diverse geographical regions and consisted of 24 original research presentations and an interdisciplinary roundtable. Specific attention was paid to the bioethical, material and lived dimensions of recent developments in molecular technologies, and discussions interrogated the complex ways in which the 'molecular realm' is an emerging site for constituting human identities in the 21st century. Herein we summarize some of the key findings of the conference and raise three further issues for practitioners and researchers to consider in relation to the broader impact of genetics research. Namely: transnational governance of emerging biotechnologies; representation of different interest groups in policy decisions; and rights of access to emerging technologies.
\end{abstract}

\section{Introduction}

The authors designed and hosted a two-day international symposium with the aim of discussing, in an interdisciplinary space, the ways in which recent advances in biological and computational technologies are changing the way different groups imagine human identities, such as race, gender, kinship, citizenship and disease risk. The event consisted of two full days, totalling eight panels of presentations. Each panel had three original presentations, and was accompanied by a senior academic acting as a discussant. Following the discussant response, there was an open discussion for each panel. The event concluded with an interdisciplinary roundtable discussion that was chaired by Sheila Jasanoff, the director of the

*Corresponding author: Tel: +1 908268 2268. E-mail: mcgonigle@ fas.harvard.edu
Program on Science, Technology and Society at the Harvard Kennedy School, which hosted the event.

The event was open to the academic community and to the wider public, and was generously supported by a range of academic departments and institutions: The Israel Institute; Harvard University's: Center for Middle Eastern Studies, the Project on Race and Gender in Science and Medicine at Hutchins Center for African \& African American Research, Edmond J. Safra Center for Ethics, Department of Anthropology, Weatherhead Center for International Affairs, Committee on Degrees in Studies of Women, Gender and Sexuality, Political Anthropology Group, Near Eastern Languages and Civilizations; The Edmond J. Safra Center for Ethics at Tel Aviv University; and Massachusetts Institute of Technology Department of Anthropology.

In this short report, we summarize the proceedings based on the panel theme titles: Nation, Values, Humanity, Nature, Genealogy, Risk, Kinship and 
Privacy. Then we reflect on some of the key issues that were raised during the discussion, emphasizing the ethical issues that arose for practitioners and researchers, and that we expect to be of special interest to the Genetics Research readership. In conclusion, we present three further issues for practitioners and researchers to consider in relation to the broader impact of genetics research. Namely: transnational governance of emerging biotechnologies; representation of different interest groups in policy decisions; and rights of access to emerging technologies.

\section{Nation}

The event commenced on a crisp April morning in Cambridge, Massachusetts, in the Malkin Penthouse of the Harvard Kennedy School's Littauer Building, which offered inspiring views of the Boston skyline and Harvard's riverside campus. After a brief introduction by the hosts, the first panel, titled 'Nation' commenced. The first presentation, by event co-organizer Ian McGonigle, analysed recent developments in national biobanking and genome projects in Israel and Qatar. He demonstrated that both national biobanks imagine participation in 'global science,' but while the Israeli National Biobank relatively proportionately represents genetic samples from the diverse ethnic groups that comprise Israel's populations, the Qatar National Biobank's samples are mostly from Qatari citizens, who are a demographic minority in the state of Qatar. This work contributes to the social theory of the 'co-production' of global science and the imagination of a national community. Laura Foster then discussed the notion that a "post-apartheid genome' in South Africa could help challenge or potentially reproduce racial apartheid categories. Such a project might subsume ethnic differences within a singular national project, and suggests that national identity need not be defined by biology. Vivette García Deister discussed how genomic storytelling practices construct Mexican mestizo identity in relation to notions of indigeneity as both mythological and pathological, simultaneously representing the Mexican population as unique and susceptible to disease. Jean Comaroff, the Alfred North Whitehead Professor of African and African American Studies and of Anthropology at Harvard University responded to this panel, raising a number of questions including whether one of the key features of the early 21 st century is the 'pathonation,' where inherited illness is used to mark naturalized, ethno-national boundaries.

\section{Values}

The second panel was themed 'Values,' and it centered on the ways genetics and genomics become privileged sites for defining and contesting human values, such as market values, nationalist values or values of belonging. Alessandro Blasimme discussed large-scale 'precision medicine' initiatives and their associated socio-technical imaginary of empowerment and selfactivated citizenship, raising issues linked to the displacement of health responsibilities from the state to individuals. Ernesto Schwartz Marin discussed the value of 'indigenous DNA' in a postcolonial Mexican state. He discussed the claim of 'genomic sovereignty' made by the Mexican state in protecting the 'Mexican DNA map' as a sovereign resource, and he emphasized the problems of representing indigenous DNA especially given that there is no indigenous political representation in the Mexican congress. Catherine Bliss discussed race, ethnicity and pharmacogenomics, illustrating how companies capitalize on a widespread desire for identity but also how individuals use medicine as a weapon in identity-based struggles. Snait Gissis, who is on the faculty at the Cohn Institute for the History and Philosophy of Science and Ideas at Tel Aviv University, acted as discussant. She raised the point that many of the terms that allow 'molecularization' of values are defined by expert interest groups with economic stakes in extracting value and resources, and that we now see neoliberal practices extended throughout the genomic sciences.

\section{Humanity}

The third panel was titled 'Humanity' and it examined how techniques to modify human biology in fundamental ways can illuminate taken for granted notions of our species identity. Ruha Benjamin (conference co-organizer, and Assistant Professor of African American Studies at Princeton University) argued that public deliberation about human gene editing must include disability justice perspectives that question basic assumptions about 'what needs to be cured' in the first place. She troubled the neat distinction between genetic therapy and human enhancement, and outlined five ways to expand a bioethical imaginary that takes the history and sociality of science seriously. Amy Hinterberger traced the connections between mythological representations of the chimera with genomic experiments that produce chimeric life such as mice with human brain cells. She explained that due, in part, to the way these entities defy neat divisions, it is difficult to regulate these practices through standard ethics review protocols. Mirko Garasic examined the use of performance enhancing drugs in Middle East armies, connecting these practices to their use in fatigue management among civilian populations - from surgeons to commercial pilots to college students. Evelynn Hammonds, 
Professor of the History of Science and African and African American Studies at Harvard University, raised an important question for all the panelists about how to broaden participation in decisions about the development and use of biotechnologies beyond scientific experts, especially given how these fields impact all of humanity.

\section{Nature}

The fourth panel on 'Nature' focused on the shifting identities of chemicals and tissues and also considered how techniques to direct and synthesize nature are sites for negotiating racial-ethnic and sexual identities. Deboleena Roy examined the identity of the chemical compound methyl isocyanate (MIC), which has impacted both life and death in Bhopal, India since the gas leak tragedy at the Union Carbide Plant in 1984. She described the seeming paradox of a growing fertility industry using Bhopali women as surrogates and how this illuminates the molecular biopolitics of the placenta as a porous boundary between transnational chemistries, women and fetuses in the context of MIC exposure. Daphna BirenbaumCarmeli, Professor at the University of Haifa, discussed the biologization of Jewish identity in Israel as it is inscribed in local reproductive technologies policies. She illustrated the incredible state investment in Jewish reproduction and the "policing of gene influx' through numerous restrictions and inducements to create the right type of biogenetic citizen and how scientists use of Zionist categories and scripts further stratify the population as they tacitly lend legitimacy to current political claims to the land. Sophia Roosth discussed how synthetic biologists employ notions of the 'natural,' 'unnatural' and 'postnatural' in engineering transgenic microbes. Drawing upon theories of queer kinship, she argued that such new life-forms undermine theories of descent, lineage and biological relatedness even in those organisms that are not modified by bioengineers. Karen SueTaussig, Professor of Anthropology at the University of Minnesota, connected the three papers with the question of the ontological politics at play when human identities are made or unmade across different settings. This prompted a conversation about the way in which human identities rely on widely stabilized and shared imaginations, and perhaps fictionalized narratives, of nature and 'the natural.'

\section{Genealogy}

This panel discussed the use of genomic sciences in the service of history, and specifically in defining ethnic and national groups. Elise Burton compared the relationship of national imaginations and genetics research in Turkey and Iran in the 20th and 21st centuries. She discussed how national genome projects produce different narratives about the ethnic and genetic diversity found within populations defined by the borders of nation states. Jessica Kolopenuk compared the production of Native American DNA with the juridical logic of Indianness in Canada - a product itself of 19 th century race science. She argued that the genetic signification of indigenous peoples operates according to a hyper-racial logic that oversimplifies and distorts indigenous practices of kinship and peoplehood. David Gurwitz discussed his experience working on population genetics of various ethnic populations. He emphasized the growing interest in India and South America in 'genetic tests for Jewish ancestry,' which he suggested may grow out of a desire to immigrate to Israel on the basis of that evidence. Maya Jasanoff, the Coolidge Professor of History and Harvard College Professor responded with the proposition that genetic technologies may be used in complex ways in crises of self-definition. She also pointed to the twin issues of power and prestige when it comes to genetic ancestry results, and she questioned 'who gains most' in the kinds of projects discussed on the panel.

\section{Risk}

Day two commenced with a coffee reception in Bell Hall in the Kennedy School's Belfer Building, and proceedings began with a panel centered on the theme of 'Risk' in relation to emerging technologies.

This panel discussed how genetic technologies may pose 'risks' to geographically, ethnically or racially segmented populations. Anna Jabloner emphasized the distinction between the elective genomic selfidentification of privileged wealthy populations, vis a vis being identified, as with forensic DNA technologies of criminalized and incarcerated populations. She also discussed the ramifications of genomic technologies on surveillance, population control and criminology, specifically in the context of the highly valued genomic industries of northern California. Yulia Egorova discussed the popular critique of genetically modified organisms (GMOs) in India, and emphasized the way in which this critique is entangled in a prior post-colonial critical discourse of global inequality and exploitation. She also discussed the pressures of being competitive on the global market, and how this force impacts the assessment of GMOs, which also bolsters collective identities. Christina Agapakis, who is the Creative Director of Ginkgo Bioworks, a synthetic biology company, presented on her experience working with scientists who anticipate and attempt to circumvent public fear of GMOs. She discussed ways that scientists' perception of public 
fears have shaped public engagement strategies as well as the technical development of genetically engineered products. She also explored artistic engagements with biotechnologies that challenge the dominant narratives of fear versus acceptance. Stephen Hilgartner, Professor of Science and Technology Studies at Cornell University, responded to the panel with the question of how identity is produced across the three presentations, suggesting that new technology becomes a resource actors use to produce or reshape 'group identities,' although not necessarily only through what the technology is designed to measure or directly affect.

\section{Kinship}

The seventh panel was on the topic of 'Kinship', and it addressed the role of biological technologies in determining rights to citizenship and their transmission to kin. The panel paid particular attention to global inequality and considered the varying ways in which authentic rights to citizenship relate to biological connections. Lidia Averbukh compared the construction of ethnic belonging in the German and Israeli Laws of Return, with a focus on the role of self-declaration, language tests and genetic kinship in these two countries. She found that whereas the state of Israel may resort to DNA tests, Germany tends to weigh cultural definitions stronger than biology. Dani Kranz described the systematic yet arbitrary bureaucracy and the resulting stress involved for parents of patrilineal Jewish children seeking Israeli citizenship, and the role of DNA testing in this process. Ari Ofengenden discussed the globalization of surrogacy and the production of Israeliness. He suggested that many people live in a 'dystopian present' and thus seek access to nation states with more advanced scientific and technological infrastructures to offset the various social crises they experience. Daphna Birenbaum-Carmeli moderated this panel discussion and put the presentations on Israel in the context of the state's demographics, its pronatalist policies and the importance placed on reproducing 'authentic' Jewish identity.

\section{Privacy}

This panel addressed the ways in which the limits of human privacy are impinged upon by advances in molecular technologies of identification, with discussions featuring: identification using DNA, and potentially RNA, tests; the Israeli biometric identification system; and the use of fMRI in measuring racial bias in behavioural neuroscience. Noam Shomron (Genetics Research, Editor-in-Chief) discussed work in his lab developing algorithms that allow for the genetic identification of individuals without measuring genes known to be involved in disease. This would be a step closer to protecting genetic privacy in relation to sensitive information about disease susceptibility, while still allowing reliable genetic identification. Michelle Spektor examined conceptions of biometric data held by opponents and proponents of the Israeli government's new biometric identification program for Israeli citizens and permanent residents, and how these conceptions relate to the ways the public debate over the program centers around issues of data risk and privacy. Oliver Rollins and Torsten Heinemann reviewed recent developments in the behavioural neuroscience of racial bias. They showed that at the level of blood flow in the brain's amygdala, it is difficult to separate an inclination towards racial bias from the display of a signal that is associated with racial bias. They therefore raised the question of whether the brain, and its internal workings, ought to remain a private domain. Sheila Jasanoff, who is also Pforzheimer Professor of Science and Technology Studies at Harvard, responded to the panel by connecting the legal and political issues across the presentations. She then posed questions to the presenters regarding what is novel about these recent technological developments, and how they fit with a longer history of legal rights to privacy.

\section{Interdisciplinary roundtable discussion and issues for further consideration}

To conclude the two days of presentations, an interdisciplinary roundtable discussion was held, with the purpose of tying the panels together, reflecting on shared issues, and considering to what extent molecular technologies are reconfiguring both individual and collective subjectivities.

Ruha Benjamin was joined by Joan Fujimura (Professor of Sociology at the University of WisconsinMadison), Snait Gissis and Sheila Jasanoff, to make short presentations in response to the conference proceedings, after which the discussion was opened to the floor.

Upon considering the most pressing issues that emerged through these discussions, here we put forward three points that we consider most relevant to practitioners, analysts and policy makers.

\section{Transnational governance}

How can science and technology be regulated across borders, since 'organisms' in nature do not recognize state borders or laws? How can a system of global governance over gene editing, synthetic biology and GMOs be constructed and maintained? What kind of political structures could represent the diverse range of stakeholders and how 
could we guarantee the implementation of its rulings?

\section{Representation}

When debating the issues and values at stake with new, or potential, biotechnologies, what sort of groups should be given representation: scientists, clinicians, elected representatives, a range of citizens or specially formed interest groups? How could existing professional associations and bodies help build such a forum?

3. Access

As the cost of DNA sequencing technologies and synthetic biology tools fall rapidly, and while their power and availability increases, who will be legally allowed to pursue genetic engineering and genetic analysis? Will we see a rise of independent citizens engaging in DIY biology? Will special protections and limitations need to be established to restrict access to certain molecular tools? These questions entail deeper questions about who owns one's body, the genetic information one carries around inside oneself, and who has the right to engage in genetic analysis or modification of oneself or others.

\section{Conclusion}

This two-day conference brought together both practitioners and analysts, from a range of disciplinary and regional backgrounds, to discuss the complex ways in which genetic technologies implicate human lives across a variety of contexts. The conference was very well attended. Due to space restrictions, the organizers were forced to limit participant registration at 140 , and indeed both days saw the conference venues full. The wide popularity of these topics speaks to both the importance of the issues being discussed, as well as the interest in interdisciplinary research at the productive intersection of the biosciences, humanities and the social sciences.

Indeed, perhaps the most significant outcome of these proceedings is that they underscore the importance of interdisciplinary collaborations and a global and historically informed outlook in relation to emerging technologies. The common thread that ties together this diverse scholarship is a concern with how recent developments are impacting the way people live their lives and experience and imagine the 'nature' of their relationships with others. We have presented here a few of the main points that emerged through the discussions that we feel will be of interest to the readership of Genetics Research. We hope the readership finds this summary useful in gauging and anticipating the importance and impact of their work outside of the university and across the globe.

\section{Declaration of interest}

This conference was kindly supported by a range of academic departments (mentioned in the introduction); however, as we received generous support from the Israel Institute, which supports scholarly work on modern Israel, research on biological technologies and their implication in Israel gained particular focus. 